\title{
Using Mediation To Defuse Potential Title VII Situations
}

Meyer Drucker, (Email: DruckerM@winthrop.edu), Winthrop University

David Stabenaw, (Email: stabenawdm@comporium.net), Winthrop University Jennifer Cooley, (Email: cooleyj6723@yahoo.com), Winthrop University

\begin{abstract}
This paper will provide an introduction to the use of mediation techniques used to defuse possible Title VII situations. The authors feel that many Title VII situations can be effectively handled through the use of properly conducted mediation. As a learning tool, students in the classroom have been given the chance to assume the role of plaintiff, defendant, lawyer and mediator. This gives the student an important insight to the situations they may be required to deal with during their careers. This paper will address several scenarios in which mediation has been undertaken, and the authors will analyze the correct methods that could have been used, as well as areas that were effectively managed. As a reference, video clips of actual mediation cases will be used to set up scenario discussions. These video clips are taken from several classroom situations that students have performed as course requirements.
\end{abstract}

\section{PART ONE: THEORY OF ALTERNATIVE DISPUTE RESOLUTION}

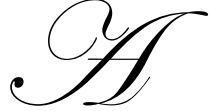

lternative Dispute Resolution (ADR) should be utilized as a more efficient and effective process in resolving disagreements that arise in employment, contractual, and other disputes. For example, employers can use ADR to help resolve issues dealing with Title VII cases as an alternative to formal litigation. These cases deal with discrimination in the workplace due to race, color, religion, gender, national origin, or age differences. ADR can save the involved parties time and money. Title VII issues arise frequently in the workplace; therefore, it is imperative to resolve employment issues promptly since waiting to resolve cases through litigation can take months or even years. As time passes, problems can escalate, such as low productivity and poor moral in the workplace. When dealing with workplace problems it is imperative to save the relationships between employers, employees, consumers, and distributors. It is likely that through ADR both parties will benefit through mutual gains, such as reaching settlements that could increase the likelihood for future business relationships. ADR is also highly preferred by the courts in order to lessen the load through pre-court settlements. The two most popular forms of ADR are mediation and arbitration.

\section{Mediation}

In mediation, a trained, neutral mediator is used to assist the parties in communicating issues in an attempt to guide them towards a mutually satisfying resolution. Unless there is a multi-party dispute, it is preferable that only the two parties, other than the mediator, be involved. The more people involved the more difficult it can be to find a resolution. Since the parties make the final decisions, a neutral mediator cannot guarantee a resolution will always be achieved. When this procedure fails, the parties frequently end up in a lengthy litigation battle, where a mutual gain for both parties is highly unlikely. Each party is permitted to bring legal counsel with them but it is often better for the parties to speak for themselves in order to preserve future relationships. Mediation is informal, allowing the parties involved to feel relaxed and more willing to work together towards a mutually acceptable resolution. All information discussed during the mediation is to be held confidential and not permitted to be used in court or any other efforts to resolve the matter. 


\section{Arbitration}

In arbitration, an arbitrator, acting more like a judge, makes the final decision. The decision may be binding in some cases but non-binding in others. Many contracts, including pre-employment contracts are binding; therefore, having legal counsel available during arbitration is a good idea. While arbitration is private and somewhat informal, it is very similar to court in that it permits the use of evidence and arguments by each party to persuade the arbitrator. Due to the arbitrator making the final decision, each party forfeits some control over the outcome. In a rare occasion, the decision could be reviewed by the courts, but more than likely it will not be overturned, unless fraud or some other unacceptable behavior is detected.

Arbitration differs from mediation because it is more like a debate than a problem solving process. Each side is arguing to convince the arbitrator they are right as opposed to mediation where the parties are trying to work together for mutual gain in the outcome. For this adversarial reason, the use of arbitration often damages a working relationship and causes problem-solving difficulties for the future.

An example of how arbitration can damage a working relationship is through the now common pre-dispute binding arbitration clauses hidden in many employment contracts. These are popular with employers to avoid litigation over Title VII cases, because of the high penalties that may be involved as a result of going to court. The use of these agreements so far has terminated many good working relationships by forcing employees to resolve disputes through binding arbitration. However, consider the EEOC v. Waffle House, Inc. 122 S. Ct. 754 (2002) case in which the employee did not arbitrate his American with Disabilities Act dispute. Instead he had the EEOC litigate a claim against Waffle House in which it was determined that the EEOC had independent statutory authority to vindicate the public interest on behalf of an employee regardless of the arbitration agreement.

Despite all the arbitration controversy, it still appears to be a popular alternative dispute resolution. It is important to understand how frequently arbitration, along with mediation, is actually conducted and to be familiar with its processes, along with some of its pitfalls.

\section{THE PROCESS}

There are six important stages to be adhered to while conducting a mediation or arbitration. Although these two methods differ in some ways, the basic negotiation procedures used are very similar, in order to achieve an efficient solution in a timely manner. Once mediation is inevitable, there are six important stages to follow including opening remarks by the mediator, opening remarks by each party, joint discussions, private discussions, joint negotiation, and closure. ${ }^{1}$

\section{Opening Remarks by the Mediator}

During this stage, the mediator begins through some opening remarks, emphasizing the importance of the proceedings, even though they will be much less formal than a court trial. Because the mediator needs to control the proceedings, certain rules must be adhered to by the parties. The mediator must convince the parties of his/her neutrality, that both parties will have their fair share of talking time, and that their goal is to reach a solution to the problem in order to avoid litigation. The mediator should emphasize that they voluntarily agreed to be there, and respectability is essential in the process in order to have a successful outcome. Outbursts and interruptions by either party will not be permitted, as those acts will only impede progress.

\section{Opening Remarks by Each Party}

Each party should be given a chance to identify what they think the problem is and given sufficient time to explain their opinion of the issues. The mediator should try to advise them away from choosing positions on each side of the problem and direct the parties on the substantive issues at hand, as opposed to placing blame. The mediator should also keep the parties actively listening to each side by summarizing their responses frequently. By summarizing frequently, the mediator can be sure that the perceptions of each side are understood. Each party should 
be attacking the issues at hand and the reasons for these issues. The disputants should avoid placing fault on anyone because this could cause one to become defensive and adhere to a position. Each party may be experiencing different emotions at this stage, therefore it remains the mediator's job to distinguish when emotions begin to run too high and call for a short break. Allowing time for breaks will help to keep emotions under control and give each party time to digest the topics being discussed, before moving to the next stage. However, in some cases intense emotions could be better in helping get to the root of the problem. If the parties show no emotion, it may be hard to envision the real perceptions that each party has. After the actual problem has been described and each party has listened to the other party's perceptions, it might be time for some brainstorming.

\section{Joint Discussions}

Now that each party has explained their perception of the problem, the issues should be discussed jointly. At this point, it may be beneficial if the parties sit side by side, if they are not already doing so. Sitting side by side influences positive outlooks while brainstorming, and lessens the possibility of developing positions. This is where the mediator should start pushing the parties to discuss their interests in the situation. Each party will have interests in a possible solution. More often than not, two parties' interests are very similar in a possible solution to a problem. For this reason, discussing interests in a solution is imperative. The mediator should remind the parties of the importance of being open minded while brainstorming. The more the parties brainstorm, the more they can "expand the pie" with more options instead of cutting the options down by being closed minded and stubborn. They need to stay focused on the important factors when brainstorming by trying to separate the people from the problem. ${ }^{2}$ They should discuss possible outcomes, with the mediator emphasizing that the outcomes are not commitments. In a negotiation, people are sometimes scared to say things because they believe that brainstorming will lock them into commitments. This is why is it so important to make sure both parties realize comments will not be held as commitments during this stage.

One should always be prepared for failure; this is extremely important for mediation negotiations. Advance planning, as to the best alternative to a negotiated agreement (BATNA), should provide the key as to whether further negotiation will be in one's best interest. It is important to be aware of this because it can be used to benchmark against trying to decide whether a party will benefit from a proposed solution or if they would benefit more from no solution. This is why the mediator needs to focus the parties on developing solutions where there is mutual gain. Mutual gain in negotiations is one of the biggest benefits of mediation. In order to preserve future negotiating relationships, it is important that both parties benefit from the outcome and no one leaves feeling cheated.

\section{Private Discussions}

When impasses are encountered, the mediator might find that private discussions with each of the parties to be extremely beneficial. These can be achieved through a caucus where the mediator sends one party out while s/he speaks to one party and then to the other. With issues that deal strongly with emotions, this method of inventing options is imperative. This gives each party the chance to speak with the mediator about their interests in an outcome without the other party interrupting or becoming defensive. The mediator should write down what is discussed, forming a type of checklist. It should include the interests of each party and what outcomes they believe could be beneficial to them. Once the mediator meets with both sides separately, s/he should have a detailed list of all interests and possible beneficial outcomes.

\section{Joint Negotiation}

The mediator should then get the parties to open up to each other on the points raised in the caucuses; the mediator should keep confidential any information uncovered during the caucuses until the parties disclose them on their own. At this point, the mediator should attempt to get the individual parties to list their own interests in outline form on paper, or preferably on a blackboard where they are negotiating. If a solution is near, the list will contain common interests and outcomes that each party would like to obtain. The mediator should explain to each side the interests of the other side; the more these interests converge, the closer you are to an agreement. The parties should negotiate towards a decision by telling each other whether they feel they can meet on common ground. 


\section{Closure}

In this stage of the mediation, the parties might solve the problem through one of the chosen options or they will decide to pursue a decision in court or through arbitration. If they chose a solution, it is probably best for the mediator to put the agreement in writing and explain it to each party. In most cases it is best that the parties sign the document, and if this is true, they may want their attorney to read over it first. If no solution is reached, the mediator may set up another session for negotiating, depending on how much progress was made during this one.

\section{PART TWO: PRACTICAL APPLICATION OF ADR TECHINIQUES}

As the first part of this paper suggests, alternative dispute resolution is widely accepted in the business world and the proper application of these techniques can provide a more harmonious work environment. As part of any labor or employment course of instruction, the use of in class mediation scenarios can be extremely beneficial to a students overall understanding of conflict resolution. In many instances, the effective implementation of mediation can avoid further problems between co-workers, unions and management, or even between customers. This portion of the paper will look into some of the mediation techniques discussed earlier in the paper, and how these techniques can be introduced to students in a classroom setting. Several video taped cases will be used to illustrate how the mediator/arbitrator can handle different parties, and how each Title VII situation can bring different challenges to the mediator/arbitrator.

\section{Case 1: Gender Discrimination}

This case involves Jane, a female employee, who wanted her company to pay tuition for her to take computer classes to increase her general knowledge. The classes were not related to her current work, and thus the request was refused. A few weeks later, another employee named John was given permission to take the same classes that Jane had requested. John has the same job title as Jane, performs the same functions, and has received about the same performance appraisals. Jane approached the EEOC about the possibility of a gender discrimination situation, and the EEOC begins its investigation.

\section{Video Clip 1}

This arbitration begins in part with a brief introduction about the basic facts of the case. Introductory remarks are generally a good way to begin this process as discussed earlier, and they can also include certain ground rules for both parties to follow. The arbitrator in this case was not overly familiar with the basic facts which can happen, but more often than not the arbitrator will have already performed an in-depth review of all case documents. Once the opening remarks are made, each of the parties was given time to make their initial statements. In this case, the EEOC contends that gender discrimination has taken place because Jane was denied funding for the same classes that John was allowed to take. The arbitrator in this case explores the reasoning behind Jane's position, and initially concludes that the company is not required to provide charity to Jane. As the arbitrator continues to ask questions of the EEOC representative, she finds out that the classes are being given to John so that he can fill a position on the night shift. Further examination finds that the company will not allow women to work at night. This fact proves to be extremely important since the company has no written policy against women working at night, and the general feeling is that women shouldn't work at night anywhere. An additional issue with this case is the fact that Jane is currently pregnant. The arbitrator does a good job trying to determine if there is a Bona Fide Occupational Qualification for the night position, which the company never establishes. The Plant Manager for this case makes a few mistakes which are common in a classroom scenario project like this. She can be seen in a couple of instances laughing, and making comments that drastically change the process. In one instance she claims the plant is now a prison, and that the main character, Jane, would be working among prison guards. Obviously, this is the type of challenge that an instructor has when dealing with student participation scenarios. The characters need to have some freedom to broaden the case, but changing the basic fact from a plant to a prison goes a little too far.

The video clip shown with this case captures the introduction, initial statements, and a small portion of the information gathering phase of the arbitration. After a lengthy discussion this situation ended with an agreement 
between the parties that the company would pay tuition for Jane to attend the courses, and a new company policy would be drafted that allowed women to work during evening hours.

\section{Case 2: Medical/Racial Dispute}

This is a two part case that contains video elements from the initial arbitration, and the awards/damages portion of the case. The first video clip will show another introductory scenario where the mediator begins with opening comments. Again, once the opening remarks are made, the two sides can begin with their statements, which in this case were started by the plaintiff. The plaintiff states that she was brought into a hospital suffering from several broken bones. The defendant, a nurse at the hospital, was said to be very rude to the plaintiff and had been counseled in the past for her rude, negligent and racist behavior. During the course of the examination the plaintiff was seated in a wheel chair that was not functioning properly, and was subsequently injured further. The nurse states that she was not rude to the plaintiff, and that a faulty wheel chair is really not her fault.

\section{Video Clip 2}

I choose this video clip for the case because of the reaction between the two parties during the information gathering phase of the mediation. As shown in the clip, there is an argument that breaks out between the two parties, which is not uncommon in a mediation such as this. As stated earlier, it is imperative that the parties try to remain calm, but should a disruption like this occur, the mediator should regain control quickly. The mediator, in this case, handled the situation immediately, which allowed the case to proceed, but had the parties continued to display this type of behavior, it is easy to see how this could have escalated.

The second video clip shows a separate part of the mediation where damages are discussed. This is included to show the final phase of the mediation which calls for both parties to come to some sort of consensus. Since this case included medical bills as well as pain and suffering, it resembles more closely an arbitration type case. That not withstanding, the principles of closing this case are much the same.

\section{Video Clip 3}

As you can see from this clip, the mediator begins by asking for possible outcomes that the plaintiff would like to see. Using the brainstorming technique, as discussed earlier, can be very beneficial to all parties involved because it can lead to an understanding of what each party is willing to accept. This technique is normally used when both parties have already agreed and are committed to this type of settlement. Absent that, it would be very difficult to use this method, and a more independent caucus might be in order. With this case however, the plaintiff and the defendant all agree that the hospital was liable for damages, and the video shows the early stages of the solution.

As the video clip suggests, the basic rules of settlement still apply in this mediation. One thing that some students may not know, and that must be stressed, is that most states allow the mediator 30 days to make an "award" decision. In these role playing scenarios it is extremely important to stress the serious nature of this negotiation process. After all of the information gathering is done, and the parties have stated their respective cases, the most uncomfortable phase is settlement itself. Many people feel uneasy when faced with making this kind of decision. Much the same way some people feel when buying a new car, negotiation is a skill that must be fine tuned. It would be hard to believe that someone would walk in off the street and pay sticker price for a car on the lot, yet many parties involved in mediation do just that. As a mediator, you should navigate both parties to a settlement that is fair and just for all.

\section{Case 3: Gender Discrimination}

Our final case involves a woman named Beth who moved from Atlanta, GA to Rock Hill, SC where she applied for a job as a heavy equipment operator with a local construction company. Beth was previously an Assistant Crew Director for an Atlanta based construction company, and she had a 2 year technical degree as well as certifications to operate many different pieces of heavy equipment. John was the construction superintendent that 
hired Beth, but initially told her she would have to start at "sign holding" duty, which required the employee to hold the stop/caution sign often seen on road construction job sites. After Beth began working, she was told by several workers that John had no intention of letting her operate the heavy equipment and that he hired her just to have "a woman" on staff. Beth quit shortly after starting and pursued a lawsuit for gender discrimination but was told that her contract required arbitration.

As this case unfolds, it seems clear that John is a male chauvinist that has a serious problem with the entire proceeding. It is not uncommon to have situations like this, which is why students should see exactly how bad some situations can get.

\section{Video Clip 4}

Although this was a simulated case, you can clearly see how John continues to "move the bar" as to what he demands from his heavy equipment operators. Beth was more than qualified as an operator, but during the information gathering John demands that his operators also be certified mechanics. John also "requires" his operators to load the equipment, but couldn't present any credible evidence as to how or when his other operators performed this task. This is very important for students to understand since many of these mediations and arbitrations are binding with limited judicial review. Because of this it is imperative that a thorough discovery process be used. As a mediator you have the authority to collect documents, conduct depositions, or anything else you think might help get a better picture of the actual situation.

The arbitrator in this case explores the hostile nature displayed by John, which can often occur during a gender discrimination case. John claims he didn't hire Beth to be a heavy equipment operator, yet the help wanted ad the company placed in the local newspaper clearly stated that he was looking for an operator. John also claims that he gave Beth a strength test to determine whether or not she could lift a certain amount of weight, but Beth disputes this, and no evidence was provided to the contrary, nor was "strength" a condition of employment listed in the help wanted ad. In the end the arbitrator decided that there was evidence of discrimination and ordered that Beth be re-instated to a heavy equipment operator position.

\section{CONCLUSIONS}

The mediation scenarios used for this paper are very real situations that could happen on any given day in the corporate world. It is imperative for those students entering the workplace, especially those with a human resource focus, to be well versed in the ways of alternate dispute resolution. As mediators and arbitrators, you should strive to ensure the highest degree of fairness and equity when resolving disputes in the workplace. As a means to that end, the Due Process Protocol is a widely accepted standard for Mediation and Arbitration of Statutory Disputes Arising Out of the Employment Relationship that was developed in 1995 by a special task force composed of individuals representing management, labor, employment, civil rights organizations, private administrative agencies, government, and the American Arbitration Association ${ }^{3}$. The Due Process Protocol, which was endorsed by the Association in 1995, seeks to ensure fairness and equity in resolving workplace disputes. The Due Process Protocol encourages mediation and arbitration of statutory disputes, provided there are due process safeguards. Examples of this can be seen in two of the cases described in this paper. The right of representation is displayed in the first case with the EEOC representing Jane. Nearly all of the negotiation was done by the EEOC representative, on Jane's behalf. Additionally, all of the cases required that information be made available to both parties involved. Since there is traditionally less time devoted to discovery in mediation, it is imperative that information be shared between the parties.

\footnotetext{
1 "Mediation FAQ." FindLaw Web Site. Retrieved 12 Dec. 04. <http://public.findlaw.com/adr/nolo/faq/>

${ }^{2}$ Fisher, Roger, and William Ury. Getting To Yes: Negotiating Agreement Without Giving In, Second Ed. New York: Penguin Group, 1991. Page 17.

${ }^{3}$ Task Force on Alternative Dispute Resolution in Employment, A Due Process Protocol for Mediation and Arbitration of Statutory Disputes Arising Out of the Employment Relationship (1995) (Employment Due Process Protocol)
} 